Ecological Society (ECOS), Nepal

www.ecosnepal.com

\title{
STUDY OF MITOTIC ACTIVITY AND CHROMOSOMAL BEHAVIOUR IN ROOT MERISTEM OF Allium cepa L. TREATED WITH MAGNESIUM SULPHATE
}

\author{
Prabhakar Bhatta and S.R. Sakya \\ Central Department of Botany \\ Tribhuvan University, Kirtipur, Kathmandu
}

\begin{abstract}
The mitotic activity and chromosomal behaviour was observed in four different concentrations of magnesium sulphate at four different duration of treatment using Allium cepa as a biological system. Mito-inhibitory effect of the compound was observed in higher concentration. The compound was capable of producing various chromosomal abnormalities indicating the cytostatic and clastogenic properties of magnesium sulphate.
\end{abstract}

Key words: Allium cepa, magnesium sulphate, mitotic index, phase indices.

\section{INTRODUCTION}

In developed agricultural systems, inorganic fertilizers are applied to the soil to supply the essential nutrients required for the growth of plants (Abraham and Nair 1989). Magnesium sulphate is not only used as fertilizer but also in the preparation of nutrient media for in vitro cultures. Cytological changes associated with application of fertilizers in soil have not been studied in detail. Fertilizers like ammonium sulphate, ammonium phosphate, ammonium nitrate and potassium chloride produced chromosome break and other abnormalities in cell divisions in Allium cepa (Abraham 1965). Other studies have demonstrated that urea induce cytological changes in Allium cepa (Chaurasia and Sinha 1987).

The present study was designed to examine the effect of magnesium sulphate on cell divisions in the root meristems of Allium cepa to reveal the cytotoxic effect and chromosonal abnormalities induced by this chemical.

\section{MATERIALS AND METHODS}

Onion (Allium cepa L.) roots were used for bioassay. Root meristem raised in water were treated with different concentrations of magnesium sulphate (viz. 0.2, 0.5, 0.8, 1\%) for different durations of time (viz. 3, 6, 12, 24 h). Root tips excised from treated and controlled materials were fixed in 1:3 acidic alcohol at 10:30 AM and preserved in $70 \%$ ethyl alcohol. Root tips squashes were made using $2 \%$ acetocarmine stain.

Different phases of mitosis were counted and chromosomal abnormalities were observed to calculate mitotic index, phase indices and total abnormality percentage at different phases.

Mitotic Index $(\mathrm{MI})=\frac{\mathrm{TDC} \times 100}{T C}$ 
Phase index $(\mathrm{PI})=\frac{T C \times 100}{T D C}$

Total percentage of Abnormal Cells $\left(\mathrm{T}_{\mathrm{Abn}}\right)=$

$$
\frac{\mathrm{TC}_{\mathrm{Abn}} \times 100}{\mathrm{TDC}}
$$

where,

$\mathrm{TDC}=$ Total dividing cells

$\mathrm{TC}=$ Total dividing and non-dividing cells

The data were subjected to statistical analysis using the Friedman's test to determine the effect of duration of treatment on the mitotic index value of root tip cells of Allium cepa L.

$\chi_{r}^{2}=\frac{12}{N K(k+1)} \sum_{j=1}^{K}(R j)^{2}-3 N(k+1)$

where,

$\mathrm{N}=$ number of rows (concentration)

$\mathrm{K}=$ number of columns (conditions, time of treatment)

$\mathrm{R}_{\mathrm{j}} \quad=$ sum of ranks in the $\mathrm{j}^{\text {th }}$ column

$\sum_{j=i}^{k}=$ Directs one to sum of the squares of the sums of ranks overall $\mathrm{k}$ conditions.

The degree of freedom (df) was determined by the reference to the Chi $(\chi)$ square distribution with $\mathrm{df}=\mathrm{k}-1$ and the significance value were matched at percentage $(\mathrm{p}<0.05)$.

\section{RESULTS}

\section{Effects in Mitotic Index}

Mitotic index value for control was 35.5. The highest MI value in treated groups was 34.5 in $0.2 \%$ concentration at $3 \mathrm{~h}$ treatment (Fig. 1). The mitotic index decreased with increase in concentration of magnesium sulphate in every duration treatment. Lowest value of mitotic index was found in $1 \%$ concentration at 24 hour's duration of treatment (Fig. 2).

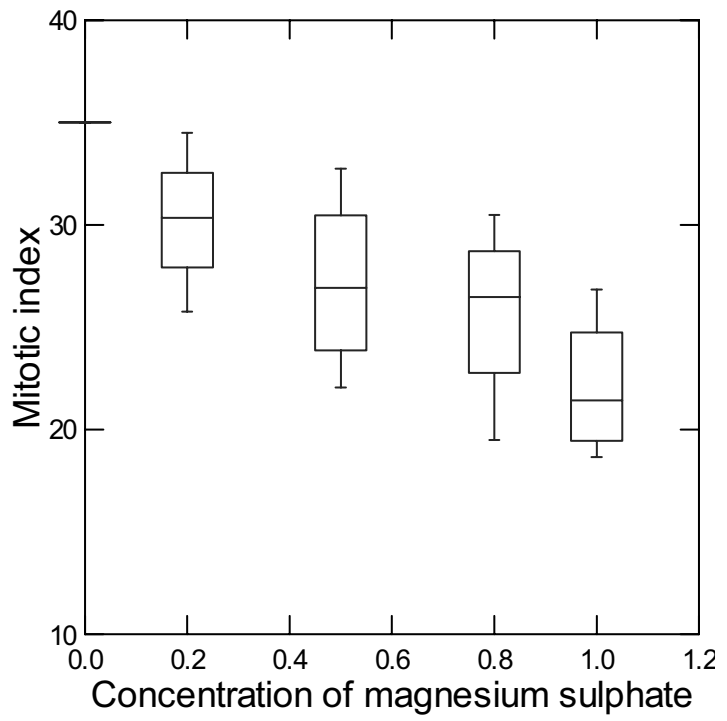

Fig. 1. Effect of concentration of Magnesium sulphate on Mitotic Index.

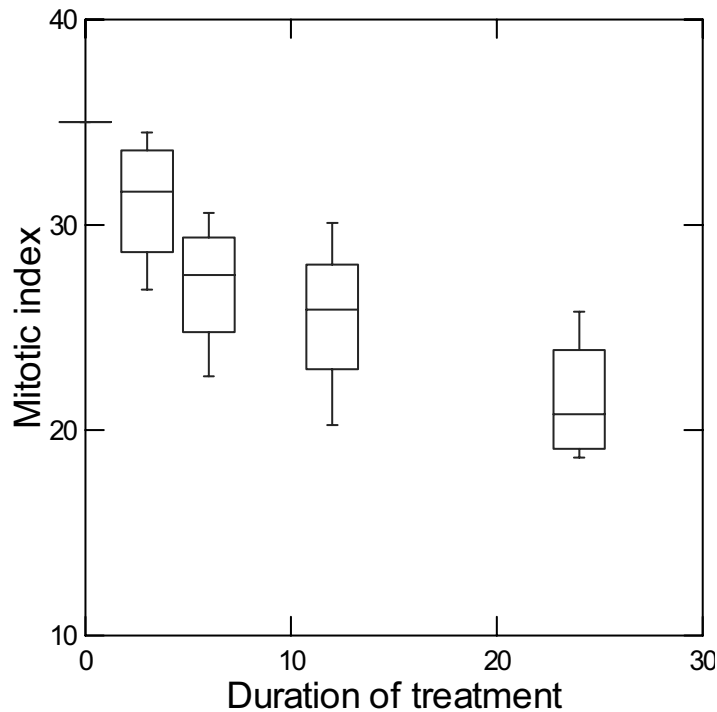

Fig. 2. Effect of duration of treatment on Mitotic Index.

\section{Effects in Prophase Index}

It has been observed that the prophase index value increased with increase in duration of treatment. The PI value of control was 85.05 and the highest value of PI, i.e., 90.5 was obtained in 
$0.8 \%$ concentration at $24 \mathrm{~h}$ duration of treatment. In majority of the cases the prophase index was higher than that of control value (Figs. 3 and 4).

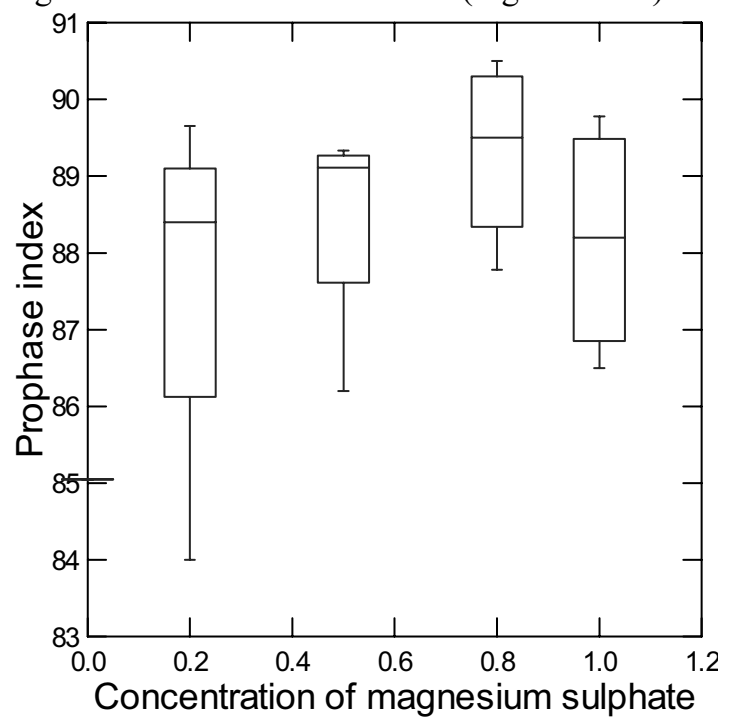

Fig. 3. Effect of concentration of Magnesium

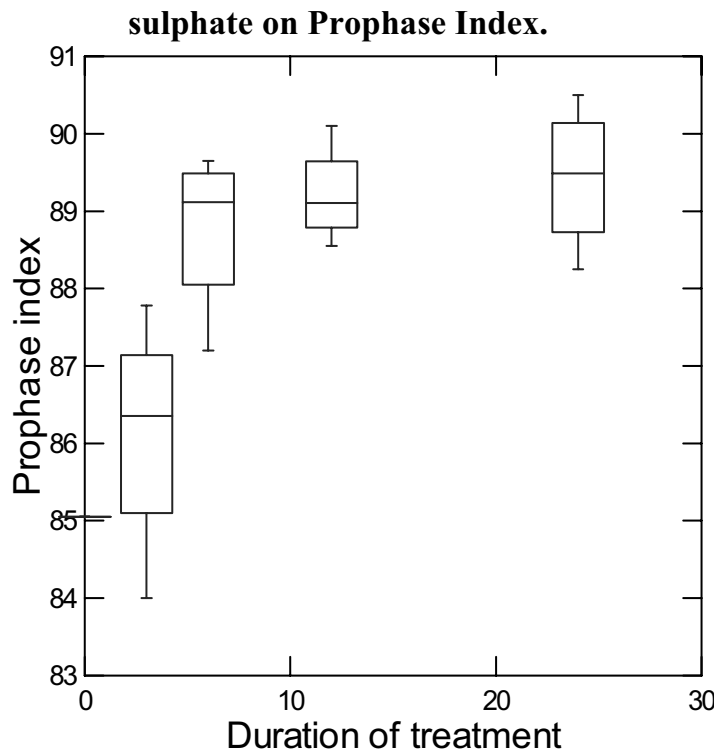

Fig. 4. Effect of duration of treatment on Prophase Index.

\section{Effects in Metaphase Index}

The metaphase index value was found maximum in $1 \%$ concentration at $6 \mathrm{~h}$ of treatment and minimum in $1 \%$ concentration at $24 \mathrm{~h}$ of ECOPRINT VOL 15, 2008 treatment. The metaphase index did not observed any regularity (Figs. 5 and 6).

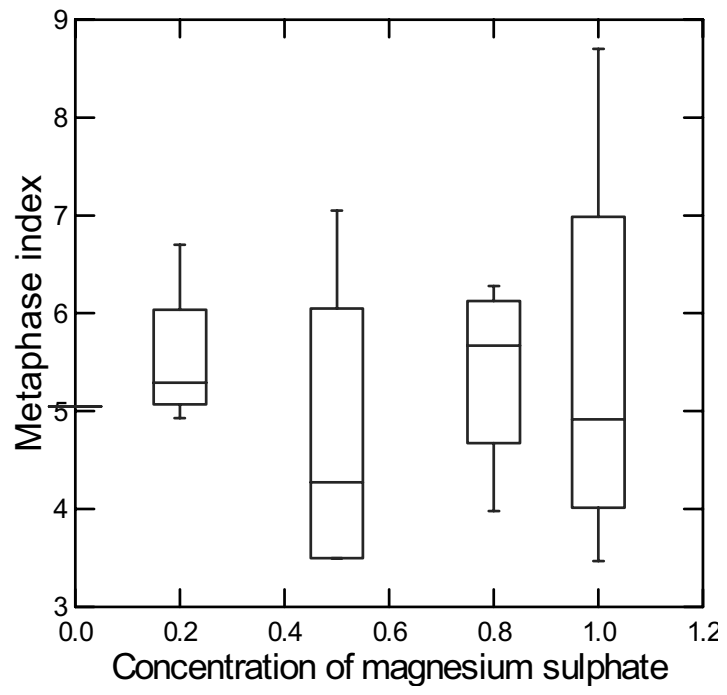

Fig. 5. Effect of concentration of Magnesium sulphate (\%) on Metaphase Index.

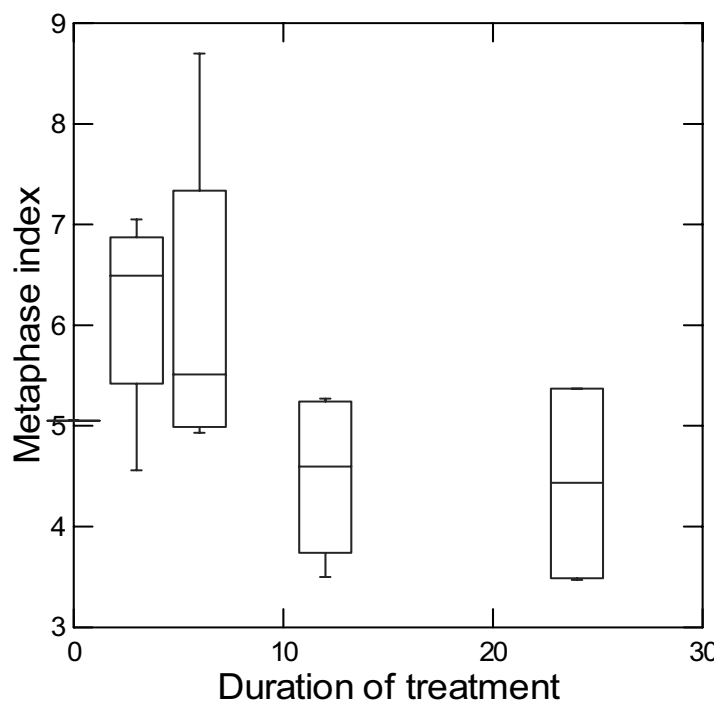

Fig. 6. Effect of duration of treatment on Metaphase Index.

\section{Effects in Anaphase and Telophase Index}

The anaphase and telophase index value was maximum in $0.2 \%$ concentration at $3 \mathrm{~h}$ of 
treatment which is lower than that of the control value. No regularity was observed in anaphase and telophase index (Figs. 7 and 8).

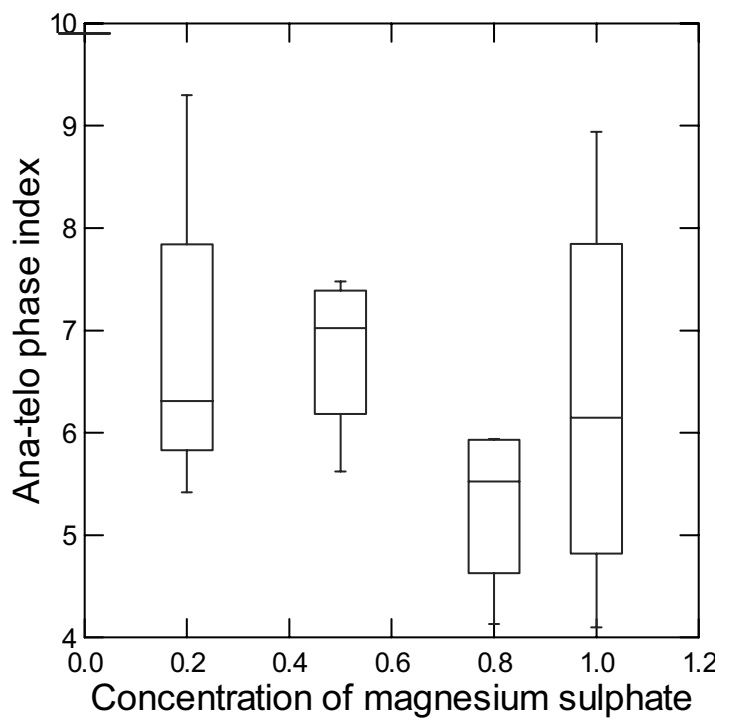

Fig. 7. Effect of concentration of Magnesium sulphate on Ana-Telophase Index.

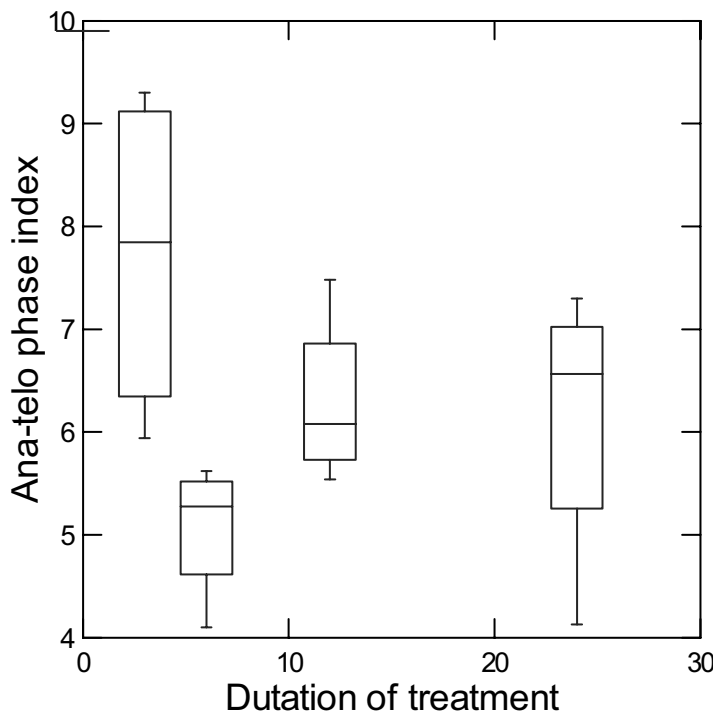

Fig. 8. Effect of duration of treatment on AnaTelophase Index.

\section{Effects in Chromosomal Behaviour}

Magnesium sulphate was capable of producing various types of chromosomal abnormalities. Roots of Allium cepa fixed without treatment showed normal divisions and only few abnormalities were observed. Clumping of chromosomes were most frequently encountered. Polar displacement, nonsynchronized arrangement of chromosomes in equatorial plate, C-metaphase and even chromosomal breaks were observed. Polar displacement, precocious arms, laggards and chromosomal bridges were observed during anaphase (Figs. 9 and 10).

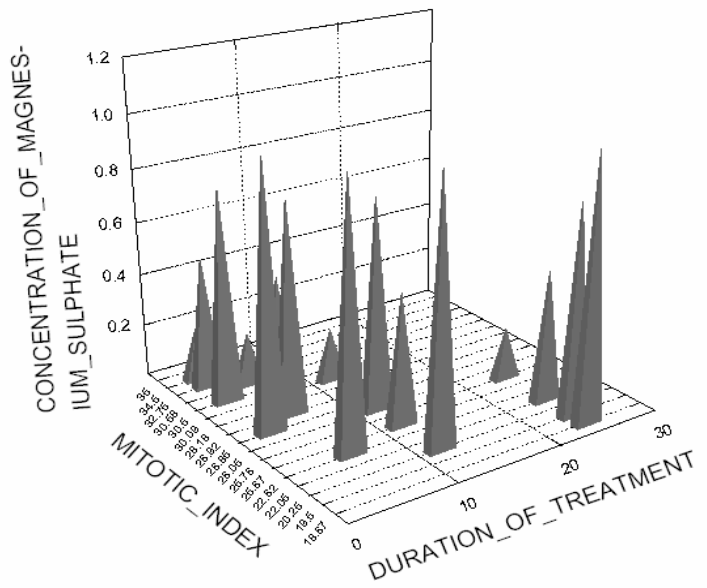

Fig. 9. 3-D pyramid of means of mitotic index with duration of treatment and concentration of magnesium sulphate.

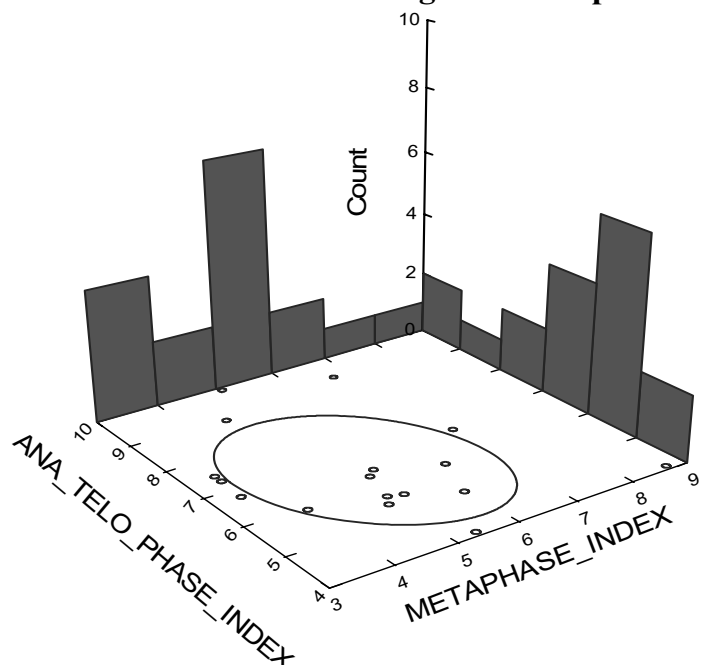

Fig. 10. Metaphase index and Ana-Telophase index. 


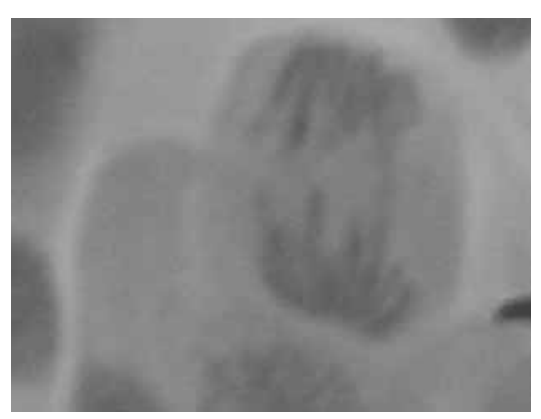

Chromosomal Bridge

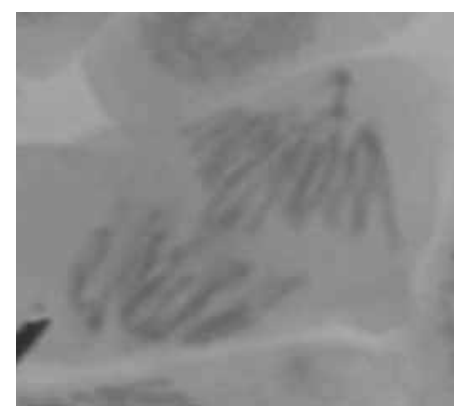

Disturbed Anaphase

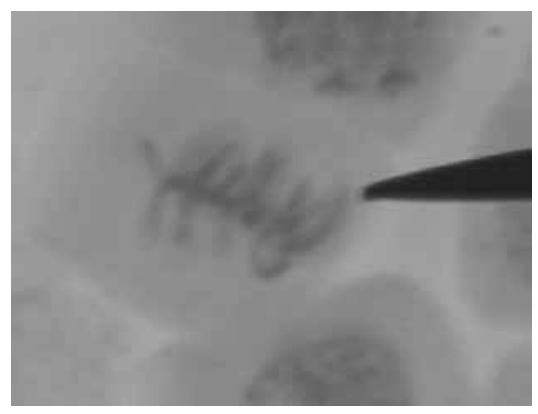

Clumped Chromosomes in Metaphase

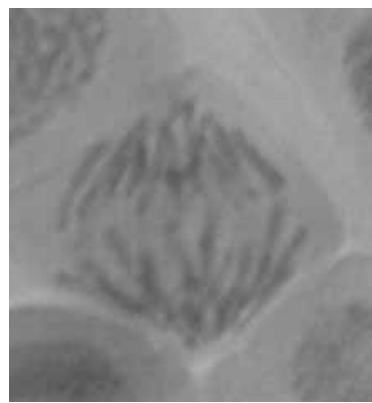

Diagonal Anaphase

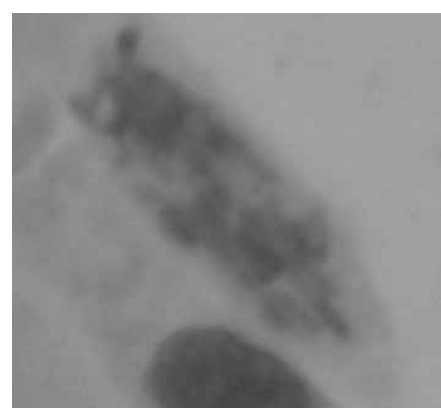

Polyploid Cell

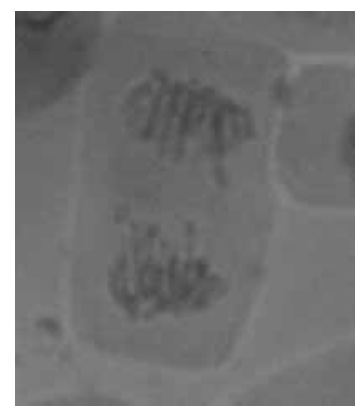

Laggards

Plate 1

\section{DISCUSSION}

It is evident from the results that the mitotic index decreased considerably in the different treatments. The drop in mitotic index is very steep in the higher concentrations of magnesium sulphate. It showed the mitodepressive activity of magnesium sulphate. Similar result were obtained by Abraham and Nair (1989) in vicia faba. The reduction in mitotic activity may result from a blocking of G1 stage suppressing DNA synthesis (Mohandas and Grant 1972).

Prophase index value increased with increase in treatment period and concentration showed the prophase poisoning where cells entered into mitosis but were arrestsed in the prophase resulting in high frequency of prophase cells (Prasad and Das 1977). 
Metaphase index showed no regularity. The abnormalities observed during metaphase were Cmetaphase, equatorial plate shifting, sticky chromosomes and non synchronized movement of chromosomes, precocious chromosomes, diagonal and disturbed anaphase were prime abnormality in anaphase. Among them, stickiness of chromosomes were frequently encountered. Stickiness is due to the inhibition of spindle formation (Amer and Ali 1986). Improper folding of chromosome fibres that makes the chromatids connected by subchromatid bridges lead to form sticky chromosomes (McGill et al. 1974).

Precocious chromosomes is the result of unequal spindle movement in which some chromosome arms are pulled towards the extremity of the pole (Pathak 1999) or it might have been caused by stickiness of chromosomes (Kaur and Grover 1985). Depolymerization of spindle fibres may cause another significant abnormality observed during both metaphase and anaphase that is shifting of poles (Mederios and Takahashi 1987).

\section{CONCLUSIONS}

Different cytological changes produced by magnesium sulphate were investigated in root meristems of Allium cepa. Higher concentration and longer duration of treatment is toxic to cells. Different concentrations of magnesium sulphate showed chromosome clumping, lagging chromosomes, chromosome breaks and equatorial plate shifting. Magnesium sulphate showed mitodepressive effect even in lower concentrations. The present study revealed cytotoxic and clastogenic properties of magnesium sulphate.

\section{ACKNOWLEDGEMENTS}

The authors are grateful to the Head, Central Department of Botany, Tribhuvan University, Kirtipur, Kathmandu.

\section{REFERENCES}

Abraham, S. 1965. Studies on spontaneous and induced mutations in plants. Cytologia 30:155-172.

Abraham, S. and R.B. Nair. 1989. Production of mitotic abnormalities by magnesium Sulphate in Vicia faba L. Cytologia 54:559-653.

Amer, S.M and E.M. Ali. 1986. Cytological study of insectide dichlorvor on the mitosis of Vicia faba. Cytologia 51:21-25.

Chaurasia, O.P. 1987. Effects of urea on mitotic chromosomes of mice and onion. Cytologia 52:877-882.

Kaur, P. and I.S. Grover. 1985. Cytological effects of some organophosphorous insecticides on the root meristem of barley (Hrodeum vulgare L.) Cytologia 50:187-197.

McGill, M., S. Pathak and T.C. Hsu. 1974. Effect of Ethidium Bromide on mitosis and chromosome. Cytologia 47:157-167.

Mederios, M.D.C. and C.S. Takahashi. 1987. Effects of Luffa operculata on Allium cepa root tips cell. Cytologia 52:255-259.

Mohandas, T. and W.F. Grant. 1972. Cytogenetic effect of 2, 4-D and amitol in relation to nuclear volume DNA content in some higher plants. Can. J. Genet. Cytologia 14:773-783.

Pathak, G.P. 1999. Study of mitotic activity and chromosomal behaviour on carmoisine treated root meristem of Allium cepa L. M.Sc. Dissertation submitted to Central Department of Botany, Tribhuvan University, Kathmandu, Nepal.

Prasad, G. and K. Das. 1977. Effects of some growth substances on mitosis. Cytologia 42:323-329 